\title{
Blood sampling - Two sides to the story
}

\author{
Pickup,La; Atkinson, $\mathrm{S}_{a} ;$ Hollnagel, $\mathrm{E}_{\mathrm{b}}$; Bowie, $\mathrm{P}_{\mathrm{c}}$; \\ Gray, $\mathrm{S}_{\mathrm{d}}$; Rawlinson, $\mathrm{S}_{\mathrm{e}}$; Forrester, $\mathrm{K}_{\mathrm{f}}$
}

Authors Details

Corresponding author*

aDr Laura Pickup

Human Factors Department

ITRC Building

The University of Nottingham

Nottingham

NG7 2RD

Email: laura.pickup@nottingham.ac.uk

Tel:07814204662

¿Professor Erik Hollnagel

Center for Quality Improvement,

Southern Region,

Denmark

Email:hollnagel.erik@gmail.com

¿Dr Paul Bowie

Safety and Improvement Research Group

Medicine Directorate

NHS Education for Scotland,

Glasgow,

United Kingdom

Institute of Health and Wellbeing,

University of Glasgow, Glasgow UK

Email:paul.bowie@nes.scot.nhs.uk

aDr Sarah Atkinson

Human Factors Department

ITRC Building

The University of Nottingham

Nottingham

NG7 2RD

Email; sarah.atkinson@nottingham.ac.uk
eDr Sam Rawlinson†

East of Scotland Blood Transfusion

Centre,

Dundee,

United Kingdom

Email: N/A

†March 2016

¿Sandra Gray

Scottish National Blood Transfusion

Service

17 Ellen's Glen Road

Edinburgh

EH17 7QT

Email:Alexandra.gray@nhs.net

fKate Forrester

Scottish National Blood Transfusion

Service

21 Ellen's Glen Road

Edinburgh

EH17 7QT

Email:Katherine.forrester@nhs.net 


\section{ABSTRACT (Words 150)}

This study aimed to investigate why there is variability in taking blood.

A multi method Pilot study was completed in four National Health Service Scotland hospitals. Human Factors/Ergonomics principles were applied to analyse data from 50 observations, 15 interviews and 12-months of incident data from all Scottish hospitals. The Functional Resonance Analysis Method (FRAM) was used to understand why variability may influence blood sampling functions.

The analysis of the 61 pre blood transfusion sampling incidents highlighted limitations in the data collected to understand factors influencing performance. FRAM highlighted how variability in the sequence of blood sampling functions and the number of practitioners involved in a single blood sampling activity was influenced by the working environment, equipment, clinical context, work demands and staff resources.

This pilot study proposes a realistic view of why blood sampling activities vary and proposes the need to consider the system's resilience in future safety management strategies.

Key Words: Blood sampling, Wrong Blood In Tube, Resilience 


\section{Word count 4153}

\section{INTRODUCTION}

In acute hospital care, the hazard of testing the wrong patient's blood, due to inaccuracies in sample labelling or patient identification creates a risk of inefficient patient care, patient harm and even death. A wrong blood in tube (WBIT) incident will influence the likelihood that a patient efficiently and safely receives the required intervention e.g. the transfusion of the correct blood component [1]. International evidence cited for WBIT incidents is between 1 in every $1,500-3,000$ of blood samples taken $[2,3]$. In the United Kingdom (UK), the Serious Hazards of Transfusion (SHOT) organisation is an independent haemovigilance scheme providing an annual comprehensive analysis and summary of national data associated with transfusion incidents. Currently data suggests few cases of major morbidity or death from WBITs, however, the potential for harm remains as the WBIT rate continues to rise [1]. In 2012 the British Committee for Standards in Haematology [4] requested that unless a secure electronic identification system was in place a second sample of the patient's blood should be requested prior to the transfusion of blood components. This recommendation is intended to mitigate the risk of harm to patients through WBIT incidents, however, it does not address why WBITs occur and hence they are likely to continue.

From a safety science perspective the most obvious questions to ask are how and why does blood sampling go wrong? There is, however, an alternative question: how and why does blood sampling usually go right? In 2014 the National Health Service (NHS) in Scotland completed 495,094 samples; for every 1 WBIT, 7583 samples were successfully processed and reported (Scottish National Blood Transfusion Service 2015). Lawton et al (2015) [5] suggests healthcare is being encouraged, like other safety industries [6], to shift safety management strategies away from solely focusing on error detection and incident management (Safety-I approach) $[6,7]$. Instead a Safety-II strategy is proposed as a more proactive approach to understand safety and increase the focus on safety interventions to ensure more things go right more often, which complements a Safety-I approach [8]. The underlying assumption of Safety-II is 
that in complex socio-technical systems adjustments to everyday working environments and human performance are normal, and are relied upon to accommodate uncertainty, fluctuations in demand and organisational constraints. Understanding these adjustments and the trade-offs made by the healthcare workforce provides a realistic view of how an organisation functions and how everyday work is usually done.

Published literature suggests two core issues impact on blood sampling system safety and reliability: patient identification and sample labelling. Formal identification of a patient underpins safety in many healthcare interventions; however, it may not always occur $[9,10,11]$. Mis-labelling of blood samples is a risk which may harm the patient or delay treatment [12, 13, 14]. Evidence reports these events but with the exception of one recent study [15] does not look to understand why. In addition incident reporting systems presents a biased interpretation of data, as reporting does not seek to capture the breadth of system related factors which influence human performance and are not representative of all types of incidents that happen $[1,16,17,18,19]$.

The aim of this pilot study is to understand why variability in blood sampling performance in acute hospital settings can occur. The methods applied were informed by Human Factors science, to understand why performance might vary and how a Safety-II approach can inform future safety management programmes.

\section{METHOD}

A three-month study at four acute medium - large hospitals in NHS Scotland was completed in 2015 involving three clinical areas which reflect those with the highest proportion of WBIT incidents [1]: Emergency departments, outpatients, and acute wards.

This study introduced the Functional Resonance Analysis Method (FRAM), an approach specifically developed to model complex systems [20]. FRAM offers a systematic approach to describing and examining work as it is done rather than imagined and reflects interactions between functions and their potential variability. 


\section{Data collection and Analysis}

The methods used to inform FRAM included observations $(n=50)$ and semi structured interviews $(n=15)$, see Table 1 . These were supported by two workshops with Transfusion Practitioners to develop and verify the findings and produce the FRAM model. The methods were completed by two researchers (LP \& SA). The approach to sampling was pragmatic and convenience sampling was necessary based on staffing levels and availability. A limited number of observations with medical doctors was possible and this informed the sampling process for the interviews completed, which recruited a greater percentage of medical staff. One year of pre blood transfusion sampling incident data $(n=61)$, from 14 regional health boards (authorities) within Scotland $(n=15)$, were also anonymised and analysed.

Table 1 Data collection details

\begin{tabular}{|c|c|c|c|}
\hline Observations & Acute Wards & Obstetrics & Outpatients \\
\hline $\begin{array}{c}\text { Emergency } \\
\text { Department }\end{array}$ & $\mathrm{n}=10$ & $\mathrm{n}=5$ & $\mathrm{n}=23$ \\
\hline $\mathrm{n}=12$ & $\begin{array}{c}\text { Healthcare } \\
\text { Support Worker }\end{array}$ & Nurse & Phlebotomist \\
\hline $\mathrm{noctor}$ & $\mathrm{n}=14$ & $\mathrm{n}=21$ & $\mathrm{n}=13$ \\
\hline $\mathrm{n}=2$ & $\begin{array}{c}\text { Healthcare } \\
\text { Support Worker }\end{array}$ & Nurse & Phlebotomist \\
\hline Interviews & 1 & 6 & 2 \\
\hline Doctor & $=484$ minutes \\
\hline 6 & 40 minutes 30 seconds \\
& $26-58$ minutes & \\
\hline $\begin{array}{l}\text { Total time } \\
\text { Average time } \\
\text { Range in time }\end{array}$
\end{tabular}

\section{Observation Data}

Observations were completed by two of researchers (LP \& SA). Fifty observations were completed (Doctors $n=2$, Healthcare Support Workers $n=14$, nurses $n=$ 21, Phlebotomists $n=13$ ) using a standardised observation tool developed specifically for the study (see online supplementary appendix A). Permission was gained from patients. A Human Factors systems model, the Systems Engineering Initiative for Patient Safety (SEIPS) model [21], was used to code observations and identify factors influencing blood sampling activities, a sample of data was double coded by two investigators (LP \& SA) to verify and modify the coding strategy. 


\section{Semi structured interviews}

Interview questions (see online supplementary appendix B) were developed following a review of the literature, they were tailored to the time available, and recorded and transcribed with permission. The analysis of the interview data informed FRAM and had two aims [20]: firstly to identify the core functions relevant to describe blood sampling activities. This was completed independently by three of the authors (LP, SA \& EH) and compared to obtain a consensus. Secondly the core functions became codes used to thematically analyse the data for sources of variability specific to each function.

\section{Incident data analysis}

Descriptive statistics were completed of the incident data and a content analysis using thematic coding [22], was completed by one investigator (LP). Level one codes represented the outcome of the incident. Level two codes were based on the SEIPS model [21]. As a pilot study the opportunity was taken to explore if this form of incident data analysis was practical and contributed to informing FRAM. This form of analysis is not essential to FRAM and project resources only allowed for one researcher to be allocated to this task. 


\section{Functional Resonance Analysis Method (FRAM)}

FRAM applied the findings from analysis of interview and observational data to describe the functions relevant to the entire blood sampling process. Each function was described using up to six aspects (Box 1); the 'output' from one function was linked as a necessary 'input' or 'precondition' for a subsequent function. A FRAM model was created within a workshop with Transfusion Practitioners using a software tool (http://functionalresonance.com/toolsvisualisation/index.html). This explored how the functions interact and which key interactions and sources of variability will potentially influence a functions 'output' -either with regard to its timing or quality.

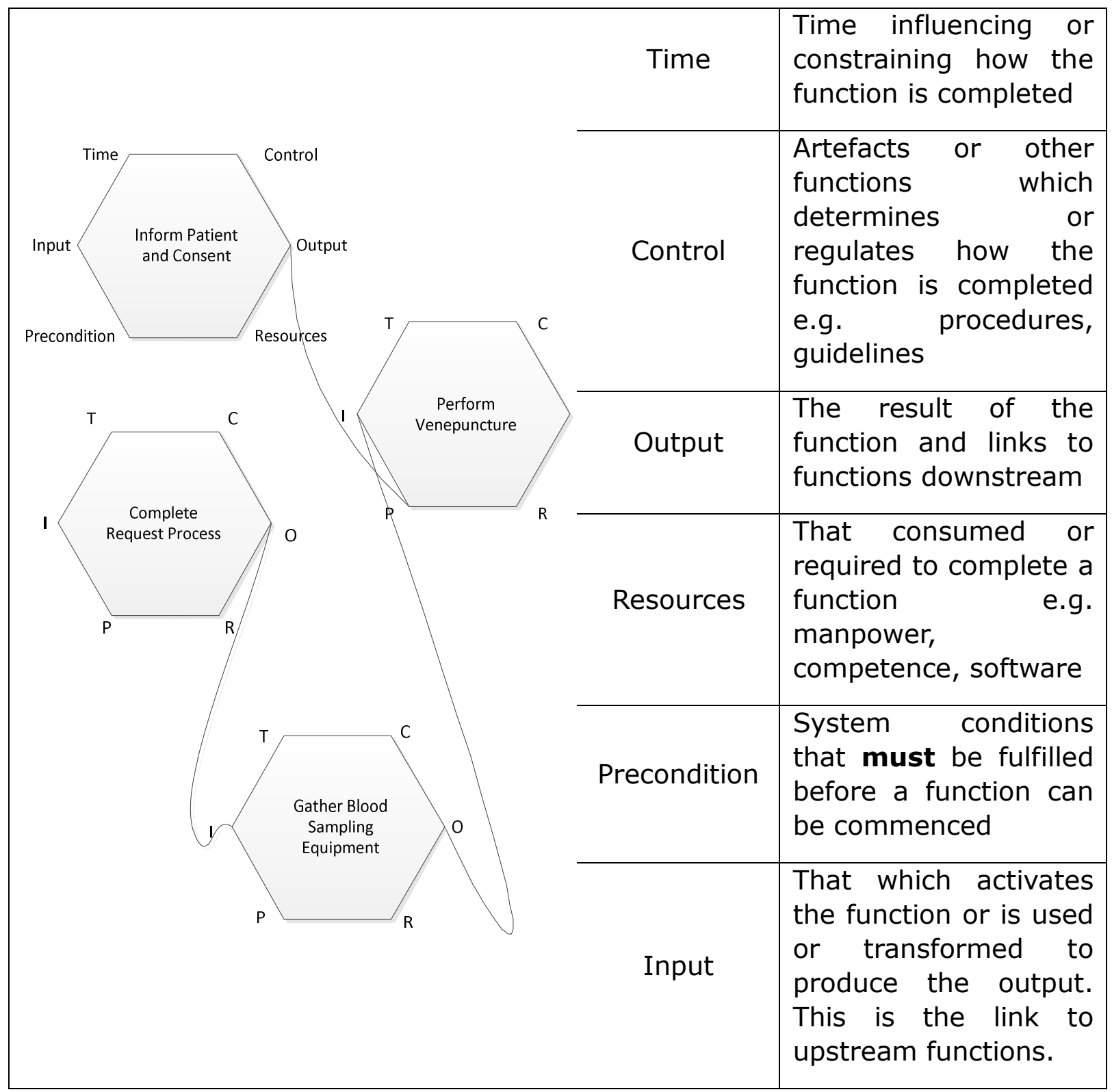

Box 1 FRAM descriptors and a sample of functions which represent the blood sampling process 
Analysis of the FRAM model focused on understanding which core functions contribute to the success of multiple subsequent functions, and combinations of closely dependent functions. The FRAM model provided a visual representation that challenged how the clinical teams believed the blood sampling procedures were applied to the reality. This verified that the final FRAM model represented what does, or potentially could, happen when blood sampling is completed rather than perceived to happen as reflected in protocols and guidance.

\section{FINDINGS}

\section{Incident Data Analysis}

\section{Job roles associated with WBIT incidents}

Descriptive statistics of the incident data supported evidence [1] on the prevalence of WBIT incidents being greater for Doctors $(42 \%)$ than Nurses (23\%), Midwifes (23\%) and Phlebotomists (3\%). However, without the frequency with which each job role takes the relative risk for each professional group can't be calculated.

The data suggests the majority of incidents occurred during normal working hours with peaks at around 12.00, and 15.00-16.00 hours, Figure 1. This may well reflect when the majority of samples are taken or be linked to other factors which may contribute to fatigue [23].

\section{WBIT outcomes and influencing factors}

Table 2 summarises the percentage split of the codes attributed to the outcome and factors influencing the incident based on the SEIPS model.

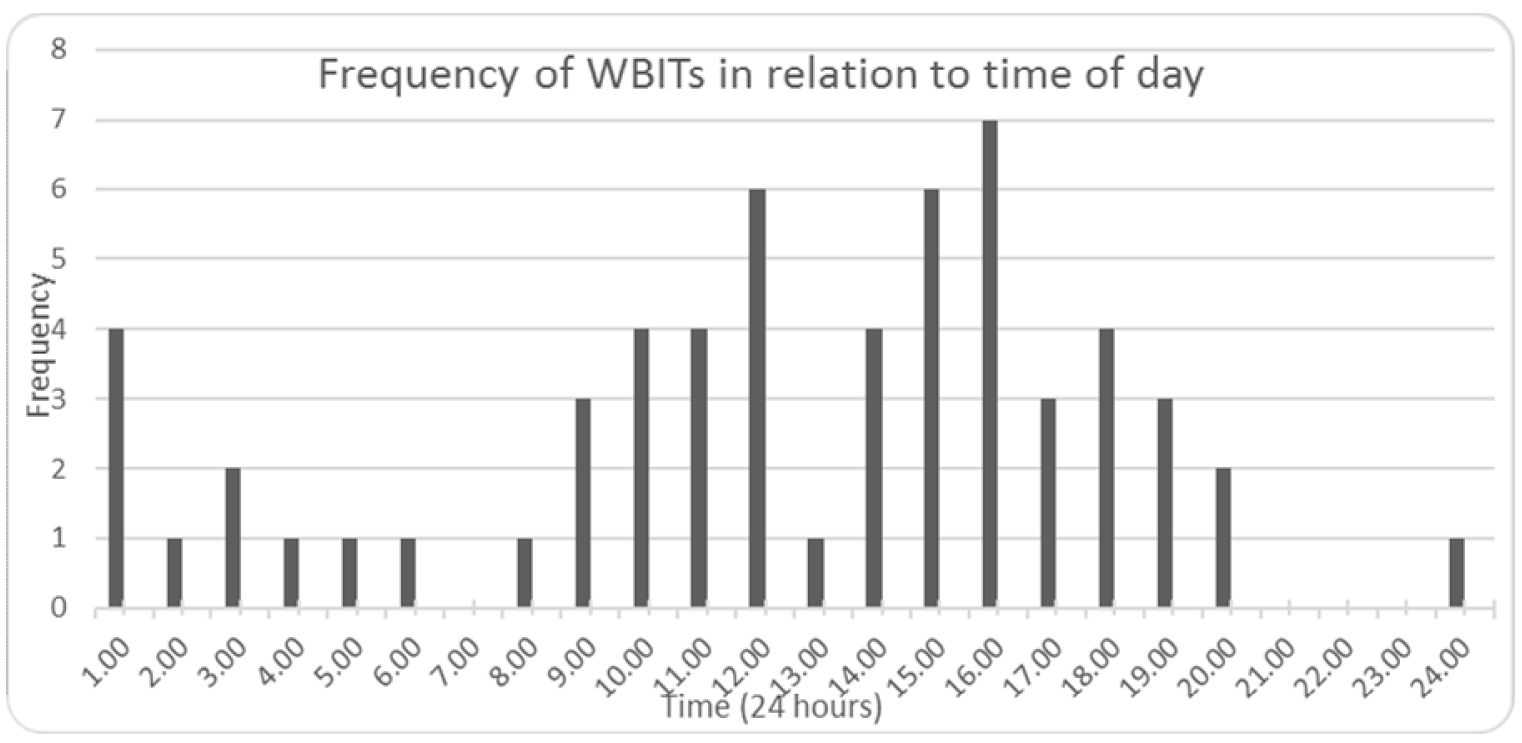


Figure 1 Time of day of WBIT incidents. 
Table 2 Systems Engineering Initiative for Patient Safety (SEIPS) Model and Incident Data Codes

\begin{tabular}{|c|c|c|c|c|}
\hline $\begin{array}{c}\text { SEIPS } \\
\text { Components }\end{array}$ & $\begin{array}{c}\text { Selection of Element } \\
\text { Examples }\end{array}$ & Wrong Label & Wrong Patient & $\begin{array}{l}\text { Wrong Patient } \\
\text { Information }\end{array}$ \\
\hline \multirow[t]{2}{*}{ Person } & \multirow{2}{*}{$\begin{array}{l}\text { Education, skills and } \\
\text { knowledge, motivation, } \\
\text { needs, physical } \\
\text { characteristics, }\end{array}$} & $9 \%$ & $32 \%$ & $25 \%$ \\
\hline & & $\begin{array}{l}\text { Fatigue, compassion for } \\
\text { patient }\end{array}$ & Alertness, fatigue & $\begin{array}{l}\text { Fatigue, fake } \\
\text { patient identity }\end{array}$ \\
\hline \multirow[t]{2}{*}{ Organisation } & \multirow{2}{*}{$\begin{array}{l}\text { Team work, communication, } \\
\text { organisational culture and } \\
\text { patient safety culture, work } \\
\text { schedules, social } \\
\text { relationships, supervisory } \\
\text { and management style }\end{array}$} & $13 \%$ & $5 \%$ & $25 \%$ \\
\hline & & $\begin{array}{l}\text { Procedure practicality, } \\
\text { training, team } \\
\text { communication, staff } \\
\text { rotation, staff resources }\end{array}$ & $\begin{array}{l}\text { Procedures - } \\
\text { practicality, team } \\
\text { work }\end{array}$ & Work schedule \\
\hline \multirow{2}{*}{$\begin{array}{l}\text { Technologies } \\
\text { and tools }\end{array}$} & \multirow{2}{*}{$\begin{array}{l}\text { Various information } \\
\text { technologies: electronic } \\
\text { health record, medical } \\
\text { devices. Other technologies } \\
\text { and tools, human factors } \\
\text { characteristics e.g. usability }\end{array}$} & $16 \%$ & $5 \%$ & $13 \%$ \\
\hline & & Unavailability, usability & Usability & Usability \\
\hline \multirow[t]{2}{*}{ Tasks } & \multirow[b]{2}{*}{$\begin{array}{l}\text { Variety of tasks, job } \\
\text { content, challenge and } \\
\text { utilisation of skills, } \\
\text { autonomy, job control and } \\
\text { participation, job demands } \\
\text { (e.g. workload, time } \\
\text { pressure, cognitive load, } \\
\text { need for attention) }\end{array}$} & $51 \%$ & $53 \%$ & $25 \%$ \\
\hline & & $\begin{array}{l}\text { Job demands, time } \\
\text { pressure, distractions, } \\
\text { interruptions, multi- } \\
\text { tasking, similar } \\
\text { information, information } \\
\text { presentation, task } \\
\text { sequence and timing }\end{array}$ & $\begin{array}{l}\text { Job demands, } \\
\text { distractions, } \\
\text { workload, similar } \\
\text { information, need } \\
\text { for attention, multi- } \\
\text { tasking }\end{array}$ & Need for attention \\
\hline
\end{tabular}




\begin{tabular}{|c|c|c|c|c|}
\hline \multirow[t]{2}{*}{ Environment } & \multirow{2}{*}{$\begin{array}{l}\text { Layout, noise, lighting, } \\
\text { temperature, humidity and } \\
\text { air quality, workstation } \\
\text { design. }\end{array}$} & $9 \%$ & $5 \%$ & $13 \%$ \\
\hline & & Noise - distractions & Noise - distractions & Noise - distractions \\
\hline \multirow{2}{*}{$\begin{array}{l}\text { Care } \\
\text { processes } \\
\text { and other } \\
\text { processes }\end{array}$} & \multirow{2}{*}{$\begin{array}{l}\text { Care processes, other } \\
\text { processes: information flow, } \\
\text { purchasing, maintenance, } \\
\text { cleaning, process } \\
\text { improvement activities }\end{array}$} & $2 \%$ & $0 \%$ & $0 \%$ \\
\hline & & $\begin{array}{l}\text { Equipment maintenance } \\
\text { and repair }\end{array}$ & & \\
\hline
\end{tabular}


The data revealed that the greatest number of incidents were associated with an outcome of the 'wrong label', these were more frequently associated with the 'task' code. This highlighted the challenge posed in the labelling of samples created from checking similar information, multi-tasking and time pressure.

Additional contributory factors were: usability of interfaces to select the correct patient from a drop down list, the presence of different patient labels in the same proximity, unavailability of technical systems, practicality of procedures and staffing levels.

\section{FRAM analysis}

A FRAM model was produced including 31 functions representative of blood sampling activity. The number of interactions between functions, upstream or downstream dependencies, are presented in Table 3 columns 2 and 3. The model was used to present two instantiations for blood sampling as observed in outpatients and reported on in an emergency situation. Variability typical to completing the core functions within these two instantiations were elicited from the data, Table 3. Interactions and dependencies between functions highlight potential differences in the sequence of functions (Table 3) and how different practitioners complete clusters of functions (see online supplementary appendix $\mathrm{C}$, each colour illustrates a different practitioner). One blood sample in the Outpatients clinic setting typically involved four practitioners and in an acute emergency situation potentially three or more. 
Table 3 Summary of function outputs and variability in blood sampling functions

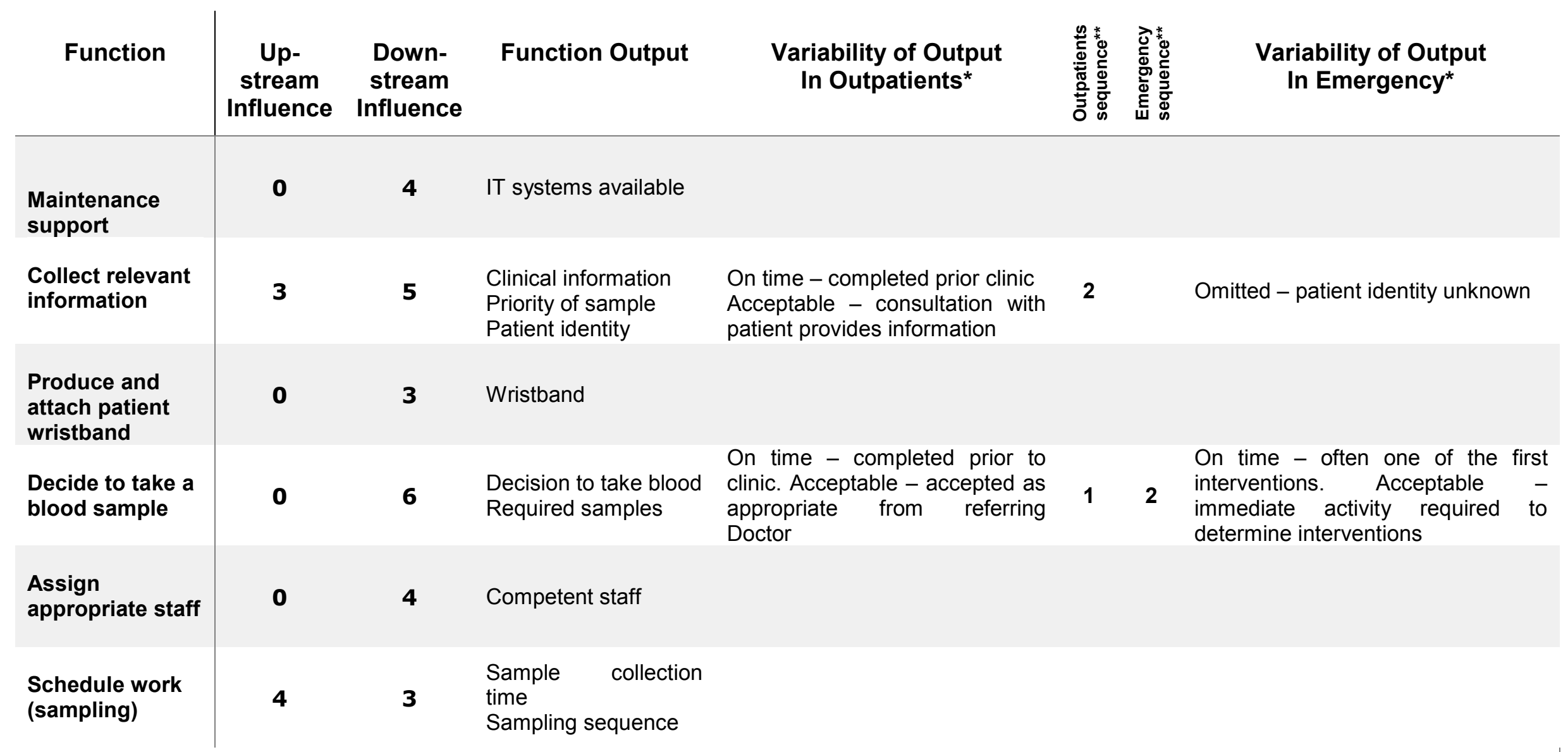

*These columns illustrate how the timing or accuracy of relevant resources and information may impede, and/or require staff to adjust the sequence or performance of the blood sampling functions. The reliability and sequence of the request and labelling of blood sample functions is determined by the clinical context and availability of technical resources.

**These columns illustrate the order in which the functions were typically observed during the study. This illustrates variability exists in the sequence of blood sampling functions between clinical contexts to obtain a sample. 


\begin{tabular}{|c|c|c|c|c|c|c|c|}
\hline Function & $\begin{array}{l}\text { Up- } \\
\text { stream } \\
\text { Influence }\end{array}$ & $\begin{array}{l}\text { Down- } \\
\text { stream } \\
\text { Influence }\end{array}$ & Function Output & $\begin{array}{l}\text { Variability of Output } \\
\text { In Outpatients }\end{array}$ & 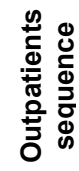 & 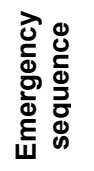 & $\begin{array}{l}\text { Variability of Output } \\
\text { In Emergency }\end{array}$ \\
\hline $\begin{array}{l}\text { Maintain } \\
\text { adequate stock } \\
\text { levels of } \\
\text { equipment }\end{array}$ & $\mathbf{0}$ & 4 & $\begin{array}{l}\text { Request forms } \\
\text { Equipment available } \\
\text { Labels, In date tubes }\end{array}$ & & & & \\
\hline $\begin{array}{l}\text { Complete } \\
\text { request process }\end{array}$ & 3 & 5 & $\begin{array}{l}\text { Written request form } \\
\text { IT system request } \\
\text { Documentation of } \\
\text { required samples }\end{array}$ & $\begin{array}{l}\text { On time - completed prior to } \\
\text { clinic. Acceptable - as patient } \\
\text { presents on clinic list requiring } \\
\text { bloods }\end{array}$ & 3 & 6 & $\begin{array}{l}\text { Imprecise - inaccuracy of } \\
\text { completion or selection of details. } \\
\text { Too late - delayed request for } \\
\text { temporary identifier }\end{array}$ \\
\hline $\begin{array}{l}\text { Print labels and } \\
\text { collect }\end{array}$ & 4 & 4 & $\begin{array}{l}\text { Labels } \\
\text { Printed labels } \\
\text { Printed IT system } \\
\text { form }\end{array}$ & $\begin{array}{l}\text { On time -printed local to clinic } \\
\text { prior to patient arrival. Precise - } \\
\text { paper clipped to patient case } \\
\text { notes used to check identity }\end{array}$ & 4 & 7 & $\begin{array}{l}\text { Too late - labels may be printed } \\
\text { after blood sampling } \\
\text { Imprecise - wrong labels printed or } \\
\text { collected }\end{array}$ \\
\hline $\begin{array}{l}\text { Check the form I } \\
\text { requests }\end{array}$ & 2 & 4 & $\begin{array}{l}\text { Documentation of } \\
\text { required samples } \\
\text { Patient identity }\end{array}$ & $\begin{array}{l}\text { On time - without check unaware } \\
\text { of patient identity requiring } \\
\text { sample }\end{array}$ & 5 & 8 & $\begin{array}{l}\text { Too late - unavailable prior to } \\
\text { sample taken }\end{array}$ \\
\hline $\begin{array}{l}\text { Gather blood } \\
\text { sampling } \\
\text { equipment }\end{array}$ & 3 & 2 & $\begin{array}{l}\text { Blood sampling } \\
\text { equipment }\end{array}$ & $\begin{array}{l}\text { On time - prepared prior to clinic } \\
\text { starting }\end{array}$ & 7 & 3 & $\begin{array}{l}\text { Too late - interrupts or delays the } \\
\text { sampling process if equipment is } \\
\text { unavailable }\end{array}$ \\
\hline Label tube & 2 & 1 & Labelled tube & & & & \\
\hline $\begin{array}{l}\text { Prepare oneself } \\
\text { for taking a } \\
\text { sample }\end{array}$ & 4 & 2 & $\begin{array}{l}\text { Preparations } \\
\text { completed } \\
\text { Clean hands, gloves }\end{array}$ & $\begin{array}{l}\text { On time - sink and equipment } \\
\text { available and accepted norm } \\
\text { within team }\end{array}$ & 10 & & $\begin{array}{l}\text { Omitted -may not be completed - } \\
\text { time pressure, patient or clinician } \\
\text { characteristics }\end{array}$ \\
\hline $\begin{array}{l}\text { Perform } \\
\text { venepuncture }\end{array}$ & 5 & 1 & Access to vein & $\begin{array}{l}\text { On time - as the resource of } \\
\text { blood sampling knowledge is } \\
\text { likely to be high in this context }\end{array}$ & 11 & 4 & $\begin{array}{l}\text { On time - as the resource of blood } \\
\text { sampling knowledge is likely to be } \\
\text { high in this context }\end{array}$ \\
\hline
\end{tabular}




\begin{tabular}{|c|c|c|c|c|c|c|c|}
\hline Function & $\begin{array}{c}\text { Up- } \\
\text { stream } \\
\text { Influence }\end{array}$ & $\begin{array}{l}\text { Down- } \\
\text { stream } \\
\text { Influence }\end{array}$ & Function Output & $\begin{array}{l}\text { Variability of Output } \\
\text { In Outpatients }\end{array}$ & 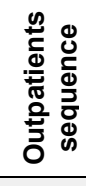 & 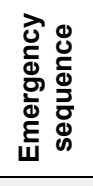 & $\begin{array}{l}\text { Variability of Output } \\
\text { In Emergency }\end{array}$ \\
\hline $\begin{array}{l}\text { Locate intended } \\
\text { patient }\end{array}$ & 4 & 1 & Location of patient & $\begin{array}{l}\text { Acceptable - called from waiting } \\
\text { room }\end{array}$ & 6 & 1 & Acceptable \\
\hline $\begin{array}{l}\text { Check identity of } \\
\text { patient }\end{array}$ & 4 & 3 & $\begin{array}{l}\text { Correctly identified } \\
\text { patient }\end{array}$ & $\begin{array}{l}\text { Imprecise - unreliable checking } \\
\text { wrong patient } \\
\text { Not at all - familiarity inhibits } \\
\text { checking. Distraction/interruption }\end{array}$ & 8 & & \\
\hline $\begin{array}{l}\text { Communicate to } \\
\text { establish identity }\end{array}$ & $\mathbf{0}$ & 3 & $\begin{array}{l}\text { Patient conformance } \\
\text { Relative conformance }\end{array}$ & & & & \\
\hline $\begin{array}{l}\text { Inform patient } \\
\text { and consent }\end{array}$ & 2 & 1 & $\begin{array}{l}\text { Permission to take } \\
\text { blood sample }\end{array}$ & $\begin{array}{l}\text { Not at all - assumed consent, } \\
\text { familiarity with patient }\end{array}$ & 9 & & \\
\hline $\begin{array}{l}\text { Label blood } \\
\text { sample }\end{array}$ & 7 & 4 & Labelled sample & $\begin{array}{l}\text { Imprecise - incorrect minimal ID } \\
\text { data set attached to sample }\end{array}$ & 13 & 9 & $\begin{array}{l}\text { Imprecise - incorrect minimal } \\
\text { ID data set attached to sample }\end{array}$ \\
\hline $\begin{array}{l}\text { Take blood } \\
\text { samples }\end{array}$ & 4 & 1 & Blood sample taken & $\begin{array}{l}\text { On time - as the resource of } \\
\text { blood sampling knowledge is } \\
\text { likely to be high in this context }\end{array}$ & 12 & 5 & $\begin{array}{l}\text { On time - as the resource of } \\
\text { blood sampling knowledge is } \\
\text { likely to be high in this context }\end{array}$ \\
\hline $\begin{array}{l}\text { Cross check } \\
\text { patient ID to } \\
\text { request }\end{array}$ & 4 & 3 & $\begin{array}{l}\text { Correctly identified } \\
\text { patient } \\
\text { Samples required }\end{array}$ & $\begin{array}{l}\text { Not at all - check of patient ID } \\
\text { omitted unintended patient } \\
\text { Imprecise - unreliable checking } \\
\text { unintended patient }\end{array}$ & & & \\
\hline Bag samples & 2 & 1 & Bagged samples & & 15 & 11 & \\
\hline
\end{tabular}




\begin{tabular}{|c|c|c|c|c|c|c|c|}
\hline Function & $\begin{array}{c}\text { Up- } \\
\text { stream } \\
\text { Influence }\end{array}$ & $\begin{array}{l}\text { Down- } \\
\text { stream } \\
\text { Influence }\end{array}$ & Function Output & $\begin{array}{l}\text { Variability of Output } \\
\text { In Outpatients }\end{array}$ & & 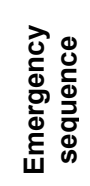 & $\begin{array}{l}\text { Variability of Output } \\
\text { In Emergency }\end{array}$ \\
\hline $\begin{array}{l}\text { Cross check } \\
\text { intended patient } \\
\text { ID on blood } \\
\text { sample }\end{array}$ & 3 & 1 & $\begin{array}{l}\text { Cross check } \\
\text { completed }\end{array}$ & & & & \\
\hline $\begin{array}{l}\text { Record samples } \\
\text { completed }\end{array}$ & 3 & $\mathbf{0}$ & Documentation & $\begin{array}{l}\text { Acceptable - record of samples } \\
\text { completed }\end{array}$ & 14 & 10 & \\
\hline $\begin{array}{l}\text { Send samples to } \\
\text { lab }\end{array}$ & 5 & 1 & Sample received & $\begin{array}{l}\text { Not at all - pod system } \\
\text { malfunctions and may prevent } \\
\text { samples reaching correct } \\
\text { destination }\end{array}$ & 16 & 12 & $\begin{array}{l}\text { Omitted - pod system } \\
\text { malfunctions and may prevent } \\
\text { samples reaching correct } \\
\text { destination }\end{array}$ \\
\hline
\end{tabular}




\section{Practitioner Resources}

The function 'Assign appropriate staff' will influence the ratio between the demand for blood samples and the ability for a healthcare system to respond. Practitioners suggested this function may compromise later checking functions.

"I like to double check and make sure I have got the right person.... in this situation that you are totally busy that kind of double checking process can sometimes go out the window"

Time pressure contributes to workload, and is a stressor which can negatively impact individual performance in tasks that rely upon attention to ensure accuracy [24]. Unpredictability in workload and availability of a venepuncturist can create real and perceived time pressures.

\section{Context of Blood Sampling}

The number of practitioners involved to complete a single blood sample varied. Instantiations (scenarios) using the FRAM model illustrated two clinical contexts. In an emergency, several practitioners may attempt to take blood, the sample might be passed to another practitioner to initiate the request process and label the bloods. Further complications or delays occur for an unidentified patient. Without the minimum patient core identifiers, practitioners are unable to access technical systems and request investigations. To enable the sample to be processed a temporary identification number is created. However, once the identity of the patient is established unique identifiers e.g. CHI or NHS numbers will be used and at some stage the patient may have two numbers.

In the first instantiation the urgency of the context justifies distributing functions within the team to allow those with clinical expertise to remain with the patient. In outpatients the demand for blood samples, time constraints and physical work environment influenced why practitioners distributed the functions.

Both strategies aimed to positively influence the system's efficiency where time was limited for different reasons. In outpatients the working practices also aimed to reduce the risks associated with checking a patient's information in a challenging working environment; where multiple practitioners work with several patients in the same workspace with distractions and interruptions. The absence of wristbands in this setting combined with time pressures and familiarity with patients, highlighted why variability in identify checks may occur. 
"I think sometimes you see so many patients you just forget (to check). Not intentionally, sometimes you think I know this patient."

\section{Information}

Three functions: 'Decide to take blood sample', 'Collect relevant information' and 'Complete request process' influenced the greatest number of other functions within the model. The expertise of the practitioner is instrumental to the decision and demand for blood samples. Increased demands were predicted as expertise fluctuates e.g. during the rotation of foundation year medical staff.

Accessibility of information was also influential to the reliability and variability associated with decision making. The usability of information sources was suggested as influential to the efficiency and accuracy with which patient details are recorded and the patient is correctly identified.

Collecting information to complete requests may be pulled from several sources. The lack of accessibility, usability and standardisation between clinical settings, were reported as influential to the accuracy and efficiency in which information can be collected.

"I have just come back from working in hospital $X$ and each of the group and save forms is different and I think that can sometimes causes bits of it not to be filled out well"

This potential for variability in collecting patient information introduces a greater dependency upon later checking to ensure a success. However, observations suggested familiarity with patients may impede this check.

\section{Labelling Blood Samples}

'Labelling the blood sample' is influenced by seven functions with the potential for variability in timing or accuracy. The dependency upon a high number of functions creates vulnerability. The quality of labelling determines efficiency and safety in management of blood samples. Hand written labels are required for samples completed prior to a blood transfusion. Incorrectly labelled samples risks a patient receiving incompatible blood components or delaying transfusions. Writing neatly on a sample bottle with a non matt, curved surface, whilst ensuring all text remains inside boxes approximately $2 \mathrm{~mm}$ high was considered a challenge. This combined with contextual factors such as time 
pressure, competing work requests and distractions were all cited as influential to variability in performance.

Printing blood sample labels is acceptable for the majority of blood tests. This requires access to technical systems, without which practitioners need to adjust the sequence of blood sampling functions. Unavailability of these systems were reported due to: system maintenance, insufficient numbers in proportion to staff working within an area, equipment failure and delayed repairs. Practitioners implied the unavailability of technology should not delay obtaining a blood sample; delays may consequently impede the transition of a patient, access to treatment or discharge from hospital. Subsequently, requests and labels may be gathered after a sample is obtained. This suggests the details on the requests and labels may not be used to inform the remaining functions associated with 'checking identity of patient'.

\section{DISCUSSION}

This pilot study sought to understand why variability in blood sampling performance in acute hospital settings can occur. The findings provide insights into why practitioners modify their work practices to manage the context and environments where blood sampling is required.

Healthcare seeks to identify a 'cause' for an accident or incident [5], with the practitioner often suggested as the more unpredictable component of the system.

This pilot study has highlighted why variability in practice is likely and is in fact the norm, with the potential for both positive and negative outcomes for patient safety and accommodating organisational demands.

An organisation or complex system is a dynamic entity which operates within a safety envelope. Gradually everyday work practices or adjustments are made to accommodate organisational priorities which will impact the decisions made daily by practitioners. The emergence of strategies can introduce 'drift' in the way work is done [25]. The term 'Resilience' or 'Resilience engineering' refers to how well a system is designed to recognise and respond to such shifts within an organisation and the impact on how a system functions. A resilient system would 
be capable of identifying and adapting to potential vulnerabilities or threats to safety without the need for an incident or accident to occur [26].

The concept of system resilience is a developing approach which informs a Safety-II approach for healthcare to consider as an alternative to improve the quality and safety of their systems by ensuring more things can go right $[8,27]$. This assumes variability in human performance is normal but aims to promote positive performance variability whilst dampening the negative.

FRAM has provided a realistic model of blood sampling to understand why variability occurs and how the system succeeds through adaptability of practitioners and where system resilience can be improved. Four key themes are proposed for further consideration to enhance the quality, safety and efficiency of blood sampling activities: design, reliability, resources and reporting.

\section{Design}

Equipment and technology relied upon within environments such as healthcare should be informed by the principles of good design [28]. These require consideration to the context, task and users to inform on a design which can promote usability, safety and efficiency [29]. The FRAM analysis highlighted how the function of 'collect relevant information' is influential to the accuracy of several other core functions. The checking of the identity of the patient is a function intended to defend against errors associated with these functions and the majority of safety interventions focus upon practitioner behaviour when labelling and checking. Evidence relating to improvement strategies for blood sampling activities highlights that several interventions in combination can have an impact upon reducing WBIT incidents, however, these are rarely maintained and a fresh look at the problem has been called for $[1,2]$.

There appeared little evidence relevant to the physical design, presentation and quality of the equipment and interface design influencing collecting the correct information. Hand writing blood sample labels on a curved and small writing surface requires physical dexterity. Combined with wearing gloves and high levels of distractions highlights how well practitioners do to succeed.

Job design should also be explored further to understand why a difference between job roles and WBIT prevalence exists. The characteristics of work 
activities and control of the timing of these activities may differ between job roles predisposing some job roles to performance influencing factors more likely to influence blood sampling activities.

Designing to make it easier to do the right thing as often as possible is at the heart of Human Factors. This would seem relevant to the design of software interfaces, request forms and blood sample bottles, which need to consider when and where blood sampling occurs and associated system hazards (e.g. time pressure, conflicting work demands), to evaluate the usability of any design and ensure risks are As Low as Reasonably Practicable (ALARP)[30].

Standardising through design can influence variability in performance. Practitioners are regularly required to rotate around hospitals or move between departments. Standardisation of the design of the artefacts that support patient safety relevant activities common to any healthcare setting could reduce variability in the format that information is presented.

\section{Reliability}

Healthcare's reliance upon technology to complete core activities will continue to increase. The instantiations captured within the FRAM model highlighted the significance of the reliability and availability of technical systems to the sequence order and adjustments necessary to complete blood sampling within a required time frame. Practitioners will delay, adjust the order or distribute functions within a team to ensure blood sampling did not delay patient care. This flexibility to adapt to technical failures was highlighted as frequent and necessary to manage patient care and work demands within care settings studies.

The resilience in systems, with increased dependency upon technology, needs to consider how to learn, monitor and respond to expected and unexpected failures or maintenance. Proactive systems to understand the risks associated with failure in technology, effective failure and maintenance reporting systems and procurement of user tested systems could benefit healthcare as it has done in high reliability industries [31]. This pilot study suggests organisational effectiveness and practitioner behaviour will both be influenced by the reliability of technology necessary to obtain relevant patient information, complete a request and label a blood sample. The ability to anticipate and respond to any 
fragility in these systems would seem to be essential but as such does not appear to be a priority.

\section{Resources}

The ratio of blood samples obtained compared to competent and confident practitioners available to complete them influenced several outputs of the functions.

The variability and potential mismatch between demand and resources was reported as influencing the time pressure and work demands for practitioners. Practitioners highlighted the need to balance patient safety when completing functions with an efficiency to ensure optimal patient care and satisfy organisational goals. An organisation may not be able to sustain an ideal ratio, however, understanding how to predict and respond to sudden or sustained mismatches may enhance resilience. Seasonal fluctuations associated with increases in patient caseload and the rotation of junior practitioners were two such examples reported as increasing the number of blood samples. A mismatch in resources and demand may influence the individual's cognitive performance and compromise the ability to remain engaged with a task, alertness, short term memory, attention and motivation levels $[24,32,33,34]$. The concept of leading indicators, where key performance indicators are identified and monitored, are used by other industries [31] to proactively identify factors predicted as likely to influence performance. Leading indicators aim to build resilience into the system with an ability to anticipate, monitor and respond in a planned way rather than rely upon frontline staff to absorb variability in the system.

\section{Monitoring, Reporting and feedback}

Incident reports and near miss data cannot be interrogated to consider how internal factors may influence variability in performance e.g. stress, fatigue, nutritional levels. There was no evidence to suggest time on duty, time since last break and factors associated with fatigue are recorded as standard practice in the healthcare settings collecting incidence data [1]. The incident analysis process will heavily influence the lessons gained by organisations to inform future interventions or strategies to manage safety concerns identified [5].

Healthcare incident data is limited by seeking a single 'cause' or deviation from expected practice with little consideration to underlying influences that contribute to the outcome recorded [19]. The SEIPs model has informed the 
analysis of incident data in this pilot study. This has provided a broader systems approach to factors recognised as influencing human performance and potentially contributing to the outcome recorded. This avoids the assumption that a single cause can always be identified and instead seeks to identify factors within a healthcare system that did/could contribute to undesirable variability in performance. The practicality of procedures for all work contexts may imply that 'noncompliance' or adjustments to the procedure is normal to everyday work practices. Furthermore, there is no process to capture positive reporting on why and how the system succeeds or indicate the success rate of different job roles in relation to the frequency of completing an activity. Proactive monitoring of performance indicators and observations or reports on everyday work can focus an organisation's attention to how safety is really achieved and where safety concerns may emerge. Timing of feedback to practitioners and how practically actions can be achieved and evaluated by an organisation to ensure an effective response addresses the contributory factors identified is instrumental to a positive reporting culture and system resilience [13].

\section{STRENGTHS AND LIMITATIONS}

A number of study strengths were apparent. We adopted a holistic Human Factors methodological perspective in trying to understand the full range of system factors which may influence variability and performance. Similarly we also applied the FRAM approach which is particularly suited to understanding why things go well in complex socio-technical systems and to address the type of safety problem at hand. The multi-professional make-up of the research team also provided a broad range of Human Factors, safety science, clinical and managerial experience and expertise.

A number of limitations were apparent. This was a pilot study and as such data collection was limited by the time and number of participants recruited for interviews and observations. The observations were focused on clinical environments reflected by NHS Scotland and within the SHOT 2013 Annual report as suggesting greater risk of WBIT [1]. Limitations in the verification of the coding of incident data have already been highlighted and require further investigation. SEIPs appears to offer codes relevant to the incident data analysed here, however, future studies are required to consider its usability for the 
analysis of all healthcare incident data and the inter and intra reliability of this approach.

It is questionable if any methodological approach can fully specify a work process in a complex socio-technical system, so it is likely that system factors of interest have yet to be captured. Given the small study scope and the focus on NHS Scotland hospitals then we should treat the findings with caution in terms of any wider generalisability, however they will still be of interest to the international practitioner, policy and research communities.

\section{CONCLUSION}

This pilot study has proposed a realistic model of blood sampling activities and why variability in performance exists. Practitioners may adjust their practice to balance patient safety in the context of fluctuating demands and challenging work environments and equipment.

Adopting a Human Factors approach and using the FRAM model has enabled the team to better understand how work is really done and why variability exists in a complex healthcare environment. The results of the study will be used to consider where resilience within the system can be enhanced.

\section{ACKNOWLEDGEMENTS}

We would like to acknowledge Douglas Watson, Diane Sydney, Lorna Sinclair, Catherine Innes, Caroline Izatt, Jane Oldham from the Scottish National Blood Transfusion Service contributions to this study. We also thank Graeme Paterson, George Brown and Calum Thomson for their feedback on the study's findings. Finally we are grateful to all the practitioners who consented to participating and thanks to Jeena Velzen's (University of Nottingham PhD student) contribution the initial review of literature.

\section{REFERENCES}

1. Bolton-Maggs, PHB, Poles D, Watt $A$ et al on behalf of the Serious Hazards of Transfusion (SHOT) Steering Group. The 2013 Annual SHOT Report 2014. 
2. Cottrell S, Watson D, Eyre TA et al. Interventions to reduce wrong blood in tube errors in transfusion: a systematic review. Transfus Med Rev 2013, $27,197-205$.

3. Dzik WH, Murphy MF, Andreu G et al. "An international study of the performance of sample collection from patients." Vox Sang 2003; 85(1):40-47.

4. British Committee for Standards in Haematology. Guideline on the Administration of Blood Components, 2012.

http://www.bcshguidelines.com/documents/Admin_blood_components_bc sh_05012010.pdf (accessed February 2nd, 2015).

5. Lawton R, Taylor N, Clay-Williams R et al. Positive deviance: a different approach to achieving patient safety. BMJ Qual Saf 2014 0:1-4. doi:10.1136/bmjqs-2014-003115.

6. Eurocontrol. From Safety-I to Safety-II: A White Paper, Eurocontrol, 2013.: 32.

https://www.eurocontrol.int/sites/default/files/content/documents/nm/saf ety/safety_whitepaper_sept_2013-web.pdf (accessed 30 ${ }^{\text {th }}$ October 2014).

7. Hollnagel E. Safety-I and Safety-II: The Past and Future of Safety Management. Farnham, UK: Ashgate 2014.

8. Hollnagel E, Braithwaite J, and Wears RL. Resilient health care. Farnham, UK: Ashgate 2013.

9. Davies A, Staves J, Kay J et al. End-to-end electronic control of the hospital transfusion process to increase the safety of blood transfusion: strengths and weaknesses. Transfusion, 2006;46: 352-364.

10. Stainsby $D$. ABO incompatible transfusions-experience from the UK Serious Hazards of Transfusion (SHOT) scheme: transfusions ABO incompatible. Transfusion clin biol 12.5 2005: 385-388.

11.Wallin O, Söderberg J, Van Guelpen B et al. Blood sample collection and patient identification demand improvement: a questionnaire study of preanalytical practices in hospital wards and laboratories. Scand J Caring Sci 24.3 2010: 581-591.

12. Lumadue JA, Boyd JS. and Ness PM. Adherence to a strict specimenlabeling policy decreases the incidence of erroneous blood grouping of blood bank specimens. Transfusion1997; 37: 1169-1172.

13.Quillen K, and Murphy K. Quality improvement to decrease specimen mislabelling in transfusion medicine. Arch Pathol Lab Med 2006;130:1196-8.

14.Gonzalez-Porras JR, GracianiI F, Alvarez Met al. "Tubes for pre transfusion testing should be collected by blood bank staff and hand labelled until the implementation of new technology for improved sample labelling. Results of a prospective study." Vox Sang 2008;95(1): 52-56.

15.Department of Health, Australia. Reducing harm in Blood Transfusion Investigating the Human Factors behind 'Wrong Blood in Tube' (WBIT) 
Events in the Emergency Department. Australia, Department of Health: 2013; 75

16. Callum JL, Lin Y, Lima AP et al. Transitioning from 'blood' safety to 'transfusion' safety: addressing the single biggest risk of transfusion. ISBT Sci Ser 2011; 6, 96-104.

17.Department of Health. An organisation with a memory, 2000. http://www.aagbi.org/sites/default/files/An\%20organisation\%20with\%20 a\%20memory.pdf (accessed on $16^{\text {th }}$ Feb 2015)

18. Kaplan HS, Battles JB, Vander Schaff TW et al. Identification and classification of the causes of events in transfusion medicine. Transfusion 1998; 38:1071-1081.

19. Taylor- Adams S and Vincent C. Systems analysis of clinical incidents; the London protocol, 2000. http://www.ihi.org/resources/Pages/Tools/SystemsAnalysisofClinicalIncide ntsTheLondonProtocol.aspx (accessed $26^{\text {th }}$ January 2015).

20. Hollnagel E. FRAM: the Functional Resonance Analysis Method. Farnham, UK: Ashgate 2012.

21. Carayon $P$, Schoofs Hundt A, Karsh B-T, et al. Work System design for patient safety: the SEIPS model. Qual Saf Healthcare 2006; 15: 50-58.

22. Miles MB and Huberman AM. An Expanded Sourcebook Qualitative Data Analysis, California, SAGE Publications 1994.

23. Health and Safety executive. The development of a Fatigue/Risk Index for Shiftworkers. Health and Safety Executive, UK, Research report 446, 2006.

24.Folkman S. Personal Control and Stress and Coping Processes: A Theoretical Analysis. J Pers and Soc Psychol 1984; 46 (4): 839-852

25.Dekker S. Resilience Engineering: Chronicling the Emergence of Confused Consensus. In: HollnagelE, WoodsDD and LevesonN eds. Resilience Engineering, concepts and Precepts 2006: 77-92.

26. Woods DD. Resilience and the ability to anticipate. In Hollnagel E, Woods DD and Wreathall J Resilience Engineering in Practice a guidebook. Farnham, UK: Ashgate 2011: 121-126.

27. Hollnagel E, Woods DD and Wreathall J .Resilience Engineering in Practice a guidebook. Farnham, UK: Ashgate 2011.

28. Department of Health and Design Council Design for Patient safety 2003. www.doh.gov.uk /designforpatientsafety (accessed on $26^{\text {th }}$ January 2015)

29.ISO/DIS6385 Ergonomic principles in the design of work systems 2014.

30.EN ISO 14971:2000. Medical Devices - Application of risk management to medical devices. 2000 .

31. Health and Safety Executive. High Reliability Organsiations - A review of the literature. Research report No. RR899;2011. 
32. Eysenck MW and Byrne A. Anxiety and susceptibility to distraction. Pers Individ Dif.1992; 13, 793-798.

33. Eysenck MW, Santos R, Derakshan R et al. Anxiety and Cognitive Performance: Attentional Control Theory. Emotion, 2007; 7: 336-353.

34. Macdonald W, Bendak S. Effects of workload level and 8-versus 12-h workday duration on test battery performance. Int J Indust Ergon 2000; 26: 399-416. 
